\section{Sartorial implications}

- The decline in the sartorial elegance often associated with the medical profession particularly in the field of obstetrics and gynaecology, seems to have accelerated over the past generation

- The wearing of bow ties has decreased

- The results of the study suggest a possible lower contamination of bow ties

- In spite of the results of this study, because of its peculiar image implications, this exquisite fashion accessory will remain confined to being worn by a small minority of bow tie connoisseurs

fluid and blood, resulting in greater contamination of conventional ties than bow ties, as suggested in this study. Greater contamination does not, however, mean that the level of cross infection in patients attended must be higher. To confirm that, a much larger study looking at infection on postnatal wards would be necessary.

A necktie is the most useless item in any man's wardrobe. It does not offer any protection against the weather or injury; it is even rather uncomfortable. Yet most men would not dream of going to work or to any special event without wearing a tie, using it as their sole opportunity to flaunt their individuality, taste, and style against the dull uniform of a suit. ${ }^{9}$ Bow ties enjoyed a bad press through the 1970 s and 1980 s unless worn with formal evening clothes: American image consultant John Molloy warned that those wearing bow ties would not be taken seriously or be trusted with anything important. ${ }^{10}$ It is therefore not surprising that most doctors lack the courage and motivation to include a bow tie in their wardrobe, and none of the doctors in the study regularly wore bow ties. In view of this, and despite the fact that all the doctors interviewed said that they would consider wearing bow ties if they proved to be more hygienic, we believe that this exquisite fashion accessory will remain confined to a small minority of connoisseurs.

We thank the participants from Arrowe Park Hospital, Birmingham Maternity Hospital, Mill Road Maternity Hospital, the Royal Liverpool University Hospital in Liverpool, HM Stanley Hospital, and St Asaph and Whiston District General Hospital for their enthusiasm; Professor John Newton for his kind comments; and Schering Health Care for their generous sponsorship of this study.

1 Byrde P. The male image. The necktie. London: Anchor Press, 1979:111-23. 2 De Marly D. Working dress. A history of occupational clothing. Bath: Bath Press, 1986.

3 Bettman OL, Hench PS. A pictorial history of medicine. Springfield, IL: C C Thomas, 1976.

4 Margotta R. An illustrated history of medicine. Feltham: Hamlyn, 1967:229.

5 Sakula A. Portraits, paintings and sculptures. London: Royal Society of Medicine, 1988:150.

6 [Editorial]. Tailor and Cutter 1990: March 18: 3.

7 Godlee R. Lister and his work. London: University of London Press, 1927: 100-2.

8 Tooley S. Life of Florence Nightingale. London: S Bousfield, 1904:119.

9 Amies H. Introduction. In: Gibbons S. The Tie. London: Studio Editions, 1990:6.

10 Molloy JT. Dress for success. New York: Warner Books, 1976:76-8.

\title{
Is Friday the 13th bad for your health?
}

\author{
T J Scanlon, Robert N Luben, F L Scanlon, Nicola Singleton
}

Abstract

Objective-To examine the relation between health, behaviour, and superstition surrounding Friday 13th in the United Kingdom.

Design-Retrospective study of paired data comparing driving and shopping patterns and accidents.

Subjects-Drivers, shoppers, and residents.

Setting-South West Thames region.

Main outcome measures-Numbers of vehicles on motorways; numbers of shoppers in supermarkets; and hospital admissions due to accidents.

Results-There were consistently and significantly fewer vehicles on the southern section of the M25 on Friday the 13th compared with Friday the 6th. The numbers of shoppers were not significantly different on the two days. Admissions due to transport accidents were significantly increased on Friday 13th (total $65 v 45 ; p<0 \cdot 05$ ).

Conclusions-Friday 13th is unlucky for some. The risk of hospital admission as a result of a transport accident may be increased by as much as $52 \%$. Staying at home is recommended.

\section{Introduction}

Superstitions affect behaviour in all cultures in all parts of the world in some form or other. Most work, however, seems to have focused on the effects of supernatural beliefs in developing countries. ${ }^{1-6}$ Perhaps there is a subconscious perception that people in the West are too sophisticated to be influenced by such trifles.
The purpose of this study was to examine the relation between health, behaviour, and superstition in the United Kingdom. To assess this, we considered the relation between accidents and Friday the 13th, which is popularly perceived to be an unlucky day.

The origins of Friday the 13th as an unlucky day are twofold: Friday and the number 13 .

\section{FRIDAY}

Now Friday came, you old wives say,

Of all the week's the unluckiest day.

The roots of Friday as an unlucky day are predominantly Christian, Good Friday being the day on which Christ was crucified. Superstitions about Friday exist in various parts of the world. Within Britain itself there are regional superstitions. ${ }^{7}$ In Somerset, whoever turns a bed on Friday turns ships at sea. In Cumberland, babies born on a Friday were laid on the family Bible. In various regions, to call a doctor for the first time on a Friday is held to be a certain omen of death for the patient. (Unfortunately the GMC is unlikely to view this as sufficient good reason for refusing a house call.) Hair and nails should never be cut on a Friday.

Why these have been chosen as unlucky if occurring on a Friday is not clear. Other superstitions around Friday have more apparent origins. For example, laundry should never be washed on a Friday. A Yorkshire legend has it that as Christ was walking to Calvary a woman washing outside her house derisively waved a wet garment at his face, whereupon he cursed her and all who should in future wash on that day. Although generally considered unlucky for weddings,
Correspondence to: Dr Scanlon. 
Friday is actually regarded by some as lucky: in Norse mythology Friday is sacred to the Goddess Freya and hence fortunate for lovers.

\section{THE NUMBER 13}

The origins of many of the superstitions around the number 13 are Christian too, mainly pertaining to the last supper when Christ dined with his 12 apostles. Even before this, the Romans disliked the number 13 as much as we do, regarding it as a symbol of death, destruction, and misfortune. ${ }^{8}$

Thirteen is widely considered an unlucky number. Houses are often not given the number 13, nor are many apartment blocks. With an eye on the market, many hotels do not have a 13th floor; the Carlton Hotel in London may have 18 floors, but the 13th is missing.

It is very unlucky for 13 people to sit down and dine together. The first to rise, like the ill fated apostle, will meet serious misfortune within the year. Few people are married on the 13th, and Friday the 13th, particularly if it falls in May, is regarded with extreme foreboding.

\section{Methods}

Gathering examples of superstition is relatively easy, but the level and effects of such superstitions on behaviour are rather more difficult to quantify. As $\mathrm{La}$ Pierre showed in the 1930s, what people say and what they do are often very different. ${ }^{9}$ To avoid this bias and to minimise costs we used routinely collected data from not so routine sources to address the following questions: just how superstitious are people and how

TABLE I-Traffic flows on southern section of M25

\begin{tabular}{lllr}
\hline & Friday 6th & Friday 13th & $\begin{array}{r}\text { Difference } \\
\text { (6th-13th) }\end{array}$ \\
\hline $\begin{array}{l}\text { July 1990 } \\
\text { Junction 7 to 8 }\end{array}$ & 139246 & 138548 & 698 \\
$\begin{array}{c}\text { Junction 9 to 10 } \\
\text { September 1991 }\end{array}$ & 134012 & 132908 & 1104 \\
$\quad$ Junction 7 to 8 & 137055 & 136018 & 1037 \\
$\quad$ Junction 9 to 10 & 133732 & 131843 & 1889 \\
December 1991 & 123552 & 121641 & 1911 \\
$\quad$ Junction 7 to 8 & 121139 & 118723 & 2416 \\
$\quad$ Junction 9 to 10 & 128293 & 125532 & 2761 \\
$\begin{array}{c}\text { March 1992 } \\
\text { Junction 7 to 8 }\end{array}$ & 124631 & 120249 & 4382 \\
$\quad$ Junction 9 to 10 & 124609 & 122770 & 1839 \\
November 1992 & Junction 7 to 8 & 117263 & 321 \\
Junction 9 to 10 & 117584 & & \\
\hline
\end{tabular}

TABLE II-Number of shoppers in nine Sainsburys supermarkets in south east England

\begin{tabular}{|c|c|c|c|c|c|c|}
\hline & \multirow{2}{*}{$\begin{array}{l}1990 \\
\text { July }\end{array}$} & \multicolumn{2}{|c|}{1991} & \multicolumn{2}{|c|}{1992} & \multirow[b]{2}{*}{ Total (mean) } \\
\hline & & September & December & March & November & \\
\hline \multicolumn{7}{|l|}{ Epsom: } \\
\hline 6th & 4942 & 4895 & 4805 & 4570 & 4506 & $23718(4744)$ \\
\hline 13th & 4882 & 4736 & 4784 & 4603 & 4629 & 23634 (4727) \\
\hline \multicolumn{7}{|c|}{ Guildford: } \\
\hline 6th & 6754 & 6704 & 5871 & 6026 & 5676 & $31031(6206)$ \\
\hline 13th & 6998 & 6707 & 5662 & 6162 & 5665 & $31194(6239)$ \\
\hline \multicolumn{7}{|c|}{ Dorking: } \\
\hline 6th & 3685 & 3799 & 3563 & 3673 & 3558 & $18278(3656)$ \\
\hline 13th & 3848 & 3680 & 3554 & 3676 & 3613 & 18371 (3674) \\
\hline \multicolumn{7}{|c|}{ Chichester: } \\
\hline 6th & 5751 & 5367 & 4949 & 5298 & 5199 & 26564 (5313) \\
\hline 13th & 5993 & 5320 & 4960 & 5467 & 5092 & $26832(5366)$ \\
\hline \multicolumn{7}{|c|}{ Horsham: } \\
\hline 6th & 4141 & 3674 & 3707 & 3633 & 3688 & $18843(3769)$ \\
\hline 13th & 4389 & 3660 & 3822 & 3730 & 3615 & $19216(3843)$ \\
\hline \multicolumn{7}{|c|}{ East Grinstead: } \\
\hline 6th & 4266 & 3954 & 4028 & 3689 & 3920 & 19857 (3971) \\
\hline 13th & 4532 & 3964 & 3926 & 3692 & 3853 & 19967 (3993) \\
\hline \multicolumn{7}{|c|}{ Lewisham: } \\
\hline 6th & 7138 & 6568 & 6514 & 6115 & 5325 & $31660(6332)$ \\
\hline 13th & 6836 & 6363 & 6555 & 6412 & 6099 & 32265 (6453) \\
\hline \multicolumn{7}{|c|}{ Nine Elms: } \\
\hline 6th & 6502 & 6416 & 6422 & 6748 & 7023 & $33111(6622)$ \\
\hline 13th & 6648 & 6398 & 6503 & 6716 & 7057 & $33322(6664)$ \\
\hline \multicolumn{7}{|c|}{ Crystal Palace: } \\
\hline 6th & 4083 & 4107 & 4168 & 4174 & 4079 & $20611(4122)$ \\
\hline 13th & 4277 & 4334 & 4050 & 4198 & 4105 & 20964 (4193) \\
\hline
\end{tabular}

does this affect their behaviour? And is Friday the 13th a more unlucky day?

We can turn the first question around and make reasonable inferences as to just how superstitious people are by examining their behaviour-for example, are people less likely to drive and shop on Friday the 13th? We looked at information from the Department of Transport on traffic flows-specifically, for the southern section of the M25, between junctions 7 and 8 and junctions 9 and 10-and from the market research department of J Sainsbury plc on the numbers of shoppers in nine different supermarkets in south east England.

To address the second question we looked at the number of admissions for accidents and poisoning in South West Thames region and at what we agreed were the particularly unlucky accidents that could occur.

The population studied broadly corresponded to the residents of South West Thames Regional Health Authority (south London, Surrey, and West Sussex). The 1991 census gave this population as 3230100 .

Because a normal distribution could not be assumed for any of the data, non-parametric methods were used in data analysis.

\section{Results}

DRIVING

Figures on traffic flows are available for the past three years (table I). Analysis did not include April 1990, the 13th of which was Good Friday. There were consistently and significantly fewer motorists on the road on Friday the 13th than on Friday the 6th $(p<0.01$, Wilcoxon signed rank test). Examination of the weather patterns for the south east did not show different weather patterns for the two Fridays. (The weather does not seem to be any more unlucky.)

Examination of the percentage fewer vehicles on the road may reveal the numbers of people less likely to drive on Friday the 13th, which may be due to superstition. There were $1.4 \%$ fewer vehicles on the southern section of the M25 on Friday the 13th-even if each vehicle had only one occupant this could mean at least $1.4 \%$ of the population are sufficiently superstitious to alter their behaviour and refrain from driving on motorways on Friday the 13th.

\section{SHOPPING}

If fewer people are driving on motorways, what are they doing instead? To examine whether they were remaining at home we looked at figures for shopping at nine supermarkets. Table II compares Friday the 13th with Friday the 6th for the five typical Friday 13ths over the past three years. In all supermarkets but one there were on average more shoppers on Friday the 13th than on Friday 6th (total average difference $0.93 \% ; \mathrm{p}<0.05)$.

\section{EMERGENCY ADMISSIONS}

Data on emergency admissions due to accidents and poisoning (main diagnosis) were available for the nine Friday the 13ths over the past five years. As coding for May 1988 and January 1989 was incomplete, these figures are not included (only one accident was recorded during these four days), nor were those for Good Friday when it fell on the 13th.

As can be seen from table III, emergency admissions with the main diagnosis of accident or poisoning were higher on Friday the 13th (mean 6) than on Friday the 6 th (mean 5). The numbers are small and the difference is not statistically significant. Therefore we looked at all admissions of South West Thames residents with a subsidiary diagnosis in specific accident categories: accidental falls (ICD E880.0E888.9); injuries caused by venomous animals and 
plants and other animals (E905.0-E906.9); injuries undetermined whether accidently or purposely inflicted (E980.0-E989.9); accidental poisoning by drugs, biological agents, other solids, gases, or vapours (E850.0-E869.9); and transport accidents (E800.0E848.9). Table IV shows these data for the six Fridays

TABLE III-Numbers of emergency admissions for accidents (including fractures) and poisoning, South West Thames region

\begin{tabular}{|c|c|c|}
\hline & Friday 6 th & Friday 13th \\
\hline \multicolumn{3}{|l|}{ 1989: } \\
\hline October & 4 & 7 \\
\hline \multicolumn{3}{|l|}{ 1990: } \\
\hline July & 6 & 6 \\
\hline \multicolumn{3}{|l|}{ 1991: } \\
\hline September & 1 & 5 \\
\hline December & 9 & 5 \\
\hline \multicolumn{3}{|l|}{ 1992: } \\
\hline March & 9 & 7 \\
\hline November & 1 & 6 \\
\hline Total (mean) & $30(5)$ & $36(6)$ \\
\hline
\end{tabular}

TABLE IV-Numbers of admissions of South West Thames residents by type of accident

\begin{tabular}{lrrrrr}
\hline & \multicolumn{2}{c}{ Friday 6th $(\mathrm{n}=6)$} & & \multicolumn{2}{c}{ Friday 13th $(\mathrm{n}=6)$} \\
\cline { 2 - 3 } \cline { 6 - 7 } Cause of accident & \multicolumn{1}{c}{ Total } & Mean & & Total & Mean \\
\hline Falling & 370 & $61 \cdot 7$ & & 343 & $57 \cdot 2$ \\
Animals & 1 & $0 \cdot 1$ & & 3 & $0 \cdot 5$ \\
Undetermined & 1 & $0 \cdot 1$ & & 4 & $0 \cdot 7$ \\
Poisoning & 37 & $6 \cdot 2$ & & 33 & $5 \cdot 5$ \\
Transport & 45 & $7 \cdot 5$ & & 65 & $10 \cdot 8$ \\
\hline
\end{tabular}

TABLE v-Numbers of admissions due to transport accidents, South West Thames region

\begin{tabular}{lcc}
\hline & Friday 6th & Friday 13th \\
\hline 1989: & & \\
October & 9 & 13 \\
1990: & & \\
July & 6 & 12 \\
1991: & & \\
$\quad$ September & 11 & 14 \\
December & 11 & 10 \\
1992: & 3 & 4 \\
March & 5 & 12 \\
November & 45 & 65 \\
\hline Total & 5 \\
\hline
\end{tabular}

used since October 1989. The only accident group that showed a statistically significant result was transport accidents, which we analysed further (table V). On five of the six Friday the 13ths there were more accidents than on the Friday the 6 ths $(p<0.05)$.

\section{Discussion}

Although the data are few and the statistical analysis simple, some tentative conclusions can be drawn.

DRIVING

Fewer people seem prepared to drive on motorways on Friday the 13th. About $1.4 \%$ of the population may be so affected. Analysis of data comparing, for example, Friday the 5 th with Friday the 12th would rule out other unrecognised reasons for weekly changes in driving patterns.

SHOPPING

The data on supermarket shopping suggest that contrary to driving on motorways, people are not deterred from shopping on Friday the 13th. Local expeditions for shopping, which may be on foot, by public transport, or by car, are not postponed.
Shopping patterns may reflect salary patterns: people paid at the end of the month may shop then and two weeks rather than one week later, when food supplies have run a bit low.

It would be interesting to know the mode of transport to these stores. Only one of the nine stores examined, Chichester, was "out of town," the others being relatively easy to reach on foot or by public transport. The results for Chichester were not significantly different from the rest $(p>0.05)$.

\section{EMERGENCY ADMISSIONS}

Although the numbers of admissions from accidents are too small to allow meaningful analysis, there seem to be more injuries from transport accidents on Friday the 13th-despite there being fewer vehicles on the road. But there are several caveats in any calculation from our data of a risk ratio for suffering a transport accident on Friday the 13th: such accidents could involve any form of transport, though motor vehicles comprise the vast majority; the accidents we recorded happened anywhere in Britain to residents of South West Thames region; the information on traffic flows refers specifically to numbers of vehicles on the southern section of the M25. That said, our data yield a risk ratio of 1.52-that is, the risk of a transport accident on Friday the 13th may be increased by $52 \%$.

\section{CONCLUSIONS}

There are four possible reasons for the findings: (i) chance: further work on larger samples would confirm or refute our evidence; (ii) confounding: some hitherto unrecognised factor may be related to both driving patterns and accident rates; (iii) bias: that those recording accident data may be more likely to record accidents on Friday the 13th; (iv) association: Friday the 13th is a more unlucky day.

Other than the people who stay off motorways, there may be people who are superstitious, but not enough to refrain from motorway driving. Do drivers on $A, B, C$, and $D$ roads alter their behaviour, and in what way? Is the alteration-for example more wariness-a positive change making them more careful and thus reducing the chance of an accident? If so, Friday the 13th may indeed be a very unlucky day. If the change in behaviour reveals itself by increased fear and anxiety, or perhaps a sense of destiny, it may reduce concentration and increase the likelihood of an accident. Are people's perceptions and beliefs self fulfilling-if you believe something strongly enough will it in fact happen to you? While we await the answers to these difficult questions we may just have to accept that Friday the 13th is indeed unlucky for some and it might be safer to stay at home.

Our thanks go to Dr Janet Peacock of St George's Medical School for her comments and guidance with the statistics; R J Beagley, group research manager of J Sainsbury plc; and Alastair Greenstreet, South East Construction Programme division, Department of Transport.

1 Gouteux IP. The supernatural, health and community action in Black Africa. Bulletin de la Société de Pathologie Exotique. 1992;85:256-60.

2 Ohaeri JU. Experience of isolated sleep paralysis in clinical practice in Nigeria. 7 Natl Med Assoc 1992;84:521-3.

F Natl Med Assoc 1992;84:521-3.
Aderinokun GA, Oyejide CO. African Dental fournal 1991;5:26-30.

3 Aderinokun GA, Oyejide CO. African Dental fournal 1991;5:26-30. classification and treatment of childhood diarthoea in highland Guatemala. Med Anthropol 1990;12:419-41.

5 Mahdihassan S. Chinese charms in the light of cosmogony. Am f Chin Med 1990;18:87-94.

6 Leygues M, Gouteux JP. A community battle against a tropical endemic disease: supernatural beliefs and tsetse fly traps in the Congo. Soc Sci Med 1989;28:1255-67.

Radford A, Radford MA. The encyclopedia of superstitions. London: Hutchinson, 1961 .

8 Lorie P. Superstitions. New York: Simon and Schuster, 1992

9 La Pierre RT. Attitudes versus actions. Social Forces 1934;13:230-7. 